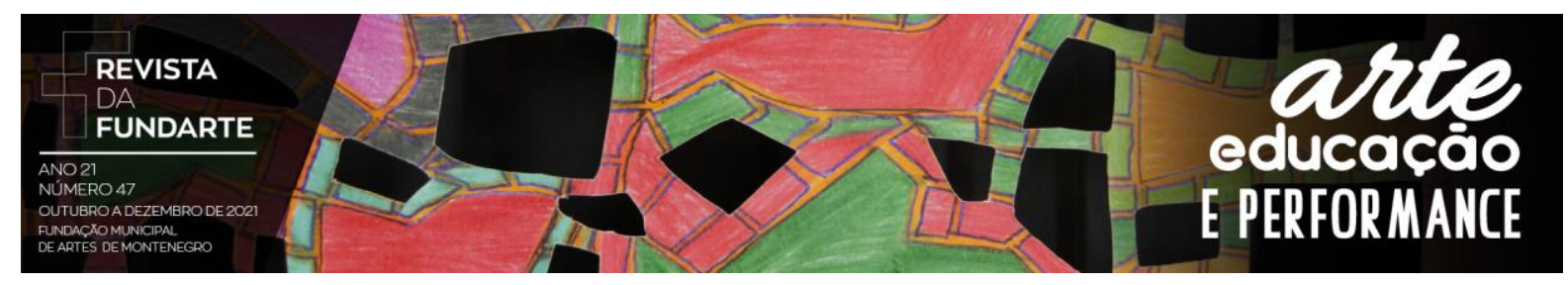

\title{
TRANSFERÊNCIAS DE ÓLEO NA OBRA DE PAUL KLEE: ESTRATÉGIA REPRODUTIVA E MEMÓRIA
}

Bethielle Amaral Kupstaitis

Resumo: O presente texto é fruto de uma reflexão acerca da técnica de transferência de imagem explorado pelo artista Paul Klee. A partir de uma série de desenhos do artista, reflete-se sobre as estratégias reprodutivas associadas ao desejo de economia de meios, compreendida como uma economia psíquica, que o conduzia a reproduzir desenhos a fim de duplicá-los ou transportá-los para outras mídias. Derivada desta dupla economia, ensaia-se a aproximação delas com o funcionamento da memória, representada pelo Wunderblock, ou bloco mágico, cujo funcionamento é descrito por Freud e associado ao funcionamento do aparelho perceptivo da mente.

Palavras-chave: Reprodução; Memória; Paul Klee.

\section{OIL TRANSFERS IN PAUL KLEE'S WORK: REPRODUCTIVE STRATEGY AND MEMORY}

\begin{abstract}
This text is the result of a reflection on the technique of image transfer explored by the artist Paul Klee. From a series of drawings of the artist, it is reflected on the reproductive strategies associated with the desire for media economy, understood as a psychic economy, which led him to reproduce drawings in order to duplicate them or transport them to other media. Derived from this double economy, their approximation to the functioning of memory, represented by wunderblock, or magic block, whose functioning is described by Freud and associated with the functioning of the perceptual apparatus of the mind.
\end{abstract}

Key-words: Reproduction; Memory; Paul Klee.

Em 2018, iniciei uma série de desenhos feitos com papel químico, mais conhecido como papel carbono. Minha motivação era explorar o preto do papel e retomar, através dos estímulos de recordação da infância, as lembranças que vem permeadas pela experiência de sujar os dedos com a matéria densa, de espessura engordurada que manchava tudo que estivesse próximo. Em contato com as mãos, o óleo impregnava e carimbava todo o tipo de superfície e reproduzia com facilidade as lições escolares da época de colégio.

O papel carbono foi muito utilizado como recurso para realização de cópias simultâneas, servindo de estratégia na economia de tempo devido a possibilidade de duplicar a ação da escrita à mão ou em máquinas de escrever. No decorrer dos 


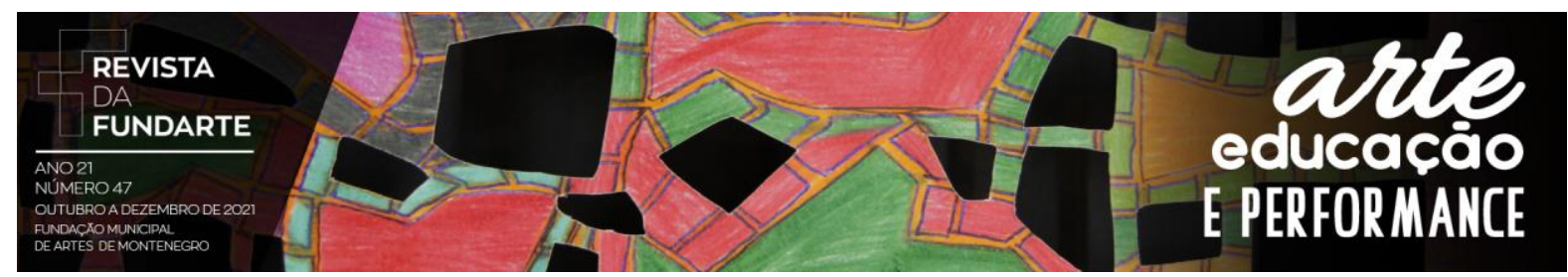

anos, com a proliferação das impressoras jato de tinta e laser, o papel carbono perdeu sua utilidade. Na atualidade, o seu legado é a abreviatura "Cc", cujo significado é "cópia em carbono" ou carbon copy. Designação usada nas cartas ou meios digitais para informar os textos em cópia.

Ao tratar dos meios de transferência de imagem, um instrumento de reprodução artesanal foi largamente explorado pelo artista Paul Klee no começo do século XX. Não por meio do papel carbono convencional como o utilizado por mim, mas através da criação de um sistema próprio cultivado pelo artista como forma de replicar suas obras. Em seu estúdio, uma pilha de desenhos foi armazenada em grandes pastas que denunciam uma prática de replicação de desenhos feitos mecanicamente pelo artista (Figura 1). A própria estrutura articulada e dobrada da volumosa pasta, pela qual os desenhos sofrem as ações do confinamento, ao serem comprimidos, dobrados, virados do avesso, servem como compreensão

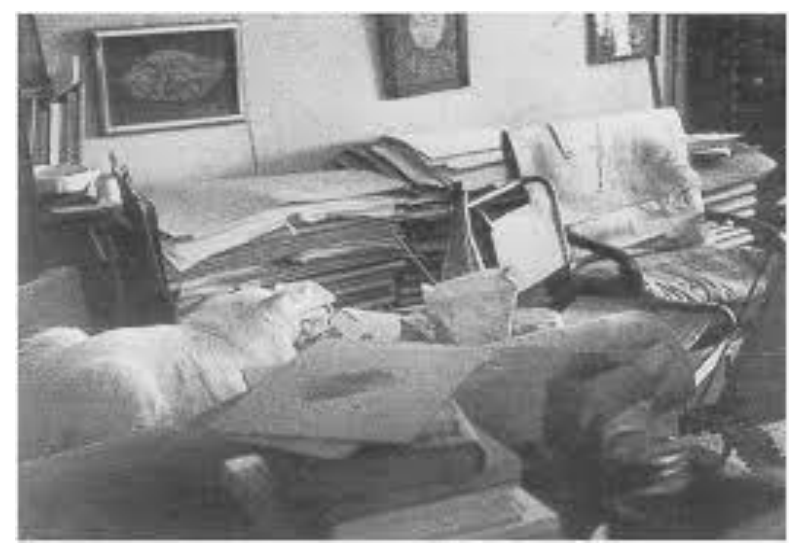

Figura 1: Fotografia das pastas de desenhos no estúdio de Paul Klee, por volta de 1940. Fonte: Zentrum Paul Klee. prévia das operações do artista ao realizar as transferências de óleo, é o que afirma Tamara Trodd, no ensaio sobre os desenhos arquivados de Paul Klee. ${ }^{1}$

A reprodução cumpre com a função de remasterizar uma linha desenhada, provocar a inversão de espelho em uma composição ou realizar a manutenção dos registros em arquivo, o que serviria para reconfigurar um desenho pré-existente. $O$ processo de duplicação consistia em pintar uma folha com tinta à óleo preto (ou tinta litográfica) e, quando estivesse quase seca, ainda viscosa, usava-a exatamente como uma folha de papel carbono, com o lado pintado virado para baixo rente ao suporte que receberia a impressão.

\footnotetext{
1 Tamara Trodd. Drawing in the archive: Paul Klee's Oil-Transfers, 2008.
} 


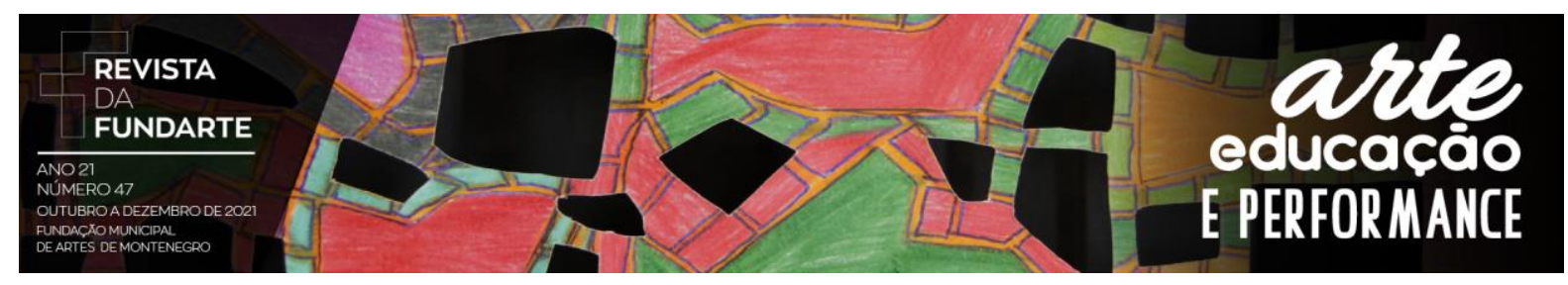

As marcas feitas com uma ponta seca transferia marcações para a folha a partir de um desenho já existente. ${ }^{2}$ Klee traçava os contornos tal qual as linhas do desenho original, mas nem sempre 0 processo ocorria da mesma forma. Para evitar que o original ficasse muito marcado ele fazia um rastreio da linha, definindo alguns pontos de referência e posteriormente ia reinscrevendo os contornos a partir das marcações estipuladas. Estes desenhos com frequência apresentam marcas de pontilhados ou vincados devido à pressão da mão do artista ao realizar as marcações. É o que se vê em Ghost of a Genius, de 1922 (Figura 2). A pressão exercida pela mão através da folha coberta de óleo transportou parte da tinta para o papel limpo. Manchas aleatórias são distribuídas pela extensão do suporte através da força de fricção exercida pela mão de Paul Klee durante o processo de rastreio das linhas.

Em Moon Play (Figura 3) é ainda mais evidente. É possível identificar com clareza os limites da folha que serviu de meio para transportar a imagem. As manchas centralizam um quadrado com

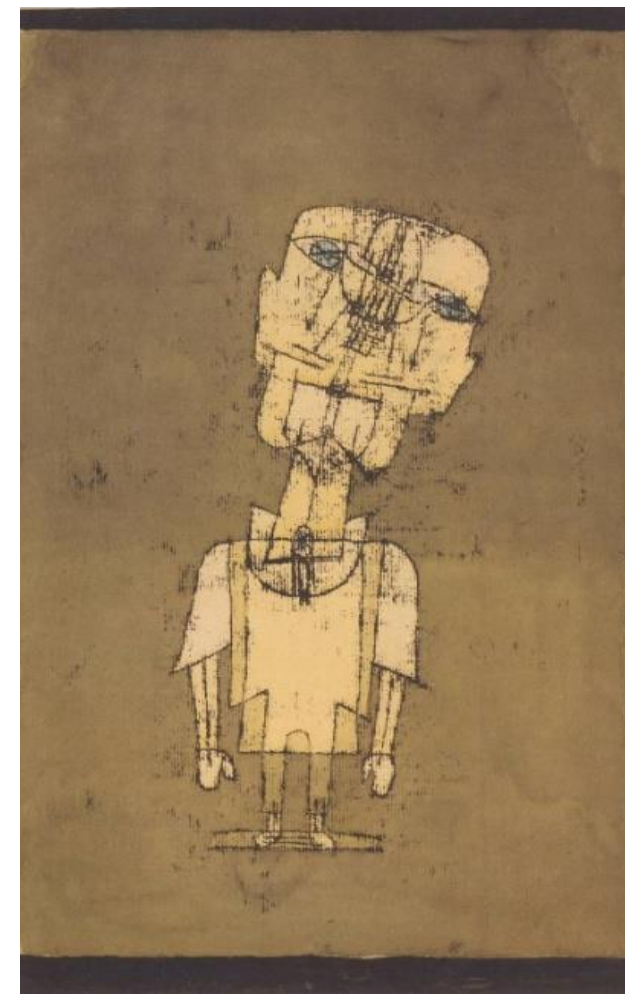

Figura 2: Paul Klee. Ghost of a Genius desenho transferido por óleo e aquarela sobre papel cartão, 1922. Fonte: Scottish National Gallery of Modern Art, Edinburgh.

Figura 3: Paul Klee. Moon Play, desenho transferido por óleo e aquarela sobre papel cartão, 1923. Fonte: Scottish National Gallery of Modern Art, Edinburgh.

2 Segundo Tamara Trodd, foi somente em 1973 que o então diretor da Fundação Klee, Jurgen Glaesemer, deu a primeira descrição completa e detalhada do procedimento. Embora alguns detalhes do processo ainda permaneçam especulativos. 


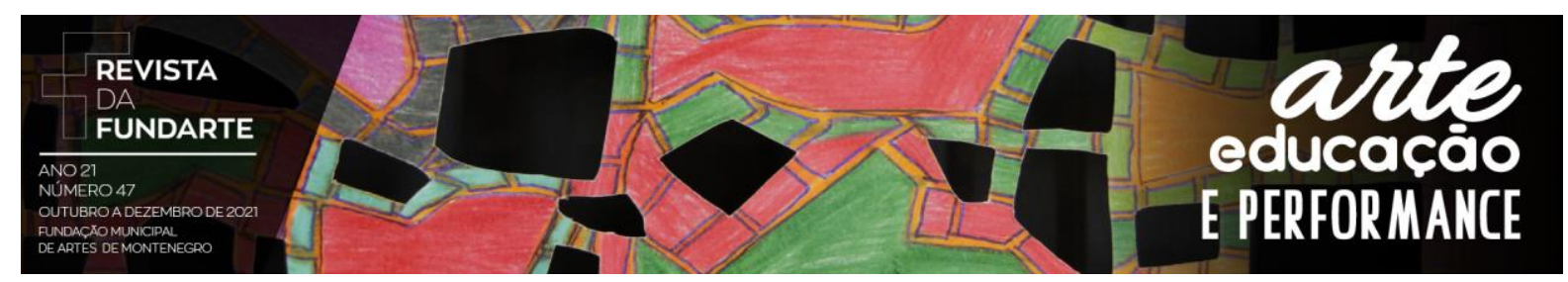

bordas pretas que denunciam a pressão do punho do artista.

As manchas podem ser observadas por toda a extensa série de desenhos que o artista executou entre os anos de 1919 a 1925. Estima-se que até 1939, quando cessaram os registros de desenhos realizados por meio de transferência, aproximadamente 350 desenhos foram feitos utilizando o mesmo procedimento, inclusive algumas de suas obras mais famosas.

Mas afinal, qual o propósito de Klee ao realizar os desenhos por transferência e por quê os armazenava em seu estúdio acumulados em pilhas? Não há uma resposta única. Argumenta-se que a técnica de transferência de Klee seria uma maneira de atribuir valor a seus desenhos na medida em que uma réplica transformava-se em pintura recebendo intervenção de mais elementos, tintas e aquarela. Esta transposição seria um meio relativamente simples de produzir mais obras em menos tempo, reciclando-as e vendendo-as como obras coloridas, portanto, únicas, retirando o seu caráter reprodutivo. Sabe-se que Klee era apegado a seus desenhos e possivelmente a invenção do processo de replicação representava a manutenção deles. Hipótese que ganha força quando se confirma que na época de sua morte, uma coleção de obras havia sido remontada por Klee desde 1920, época em que o artista iniciou deliberadamente a reter seus trabalhos do olhar do público, recusando-se a exibi-los ou vendê-los. Felix Klee teria dito posteriormente que o processo utilizado pelo pai tinha relação ao fato de Klee não suportar separar-se de seus desenhos, uma manifestação de apego que o motivaria a replicá-los.

O processo de transferência por óleo está subjugado a uma economia de meios, ou seja, uma estratégia de processamento das imagens existentes. Os desenhos cultivados no arquivo de Klee poderiam ser facilmente revertidos ou reproduzidos em um original não invertido. $\mathrm{O}$ artista tinha a liberdade de criar a partir de um desenho original ao mesmo tempo que o mantinha preservado. Quando Tamara Trodd ressalta o sentido da palavra "economia" ao abordar a operação de Klee, ela argumenta 


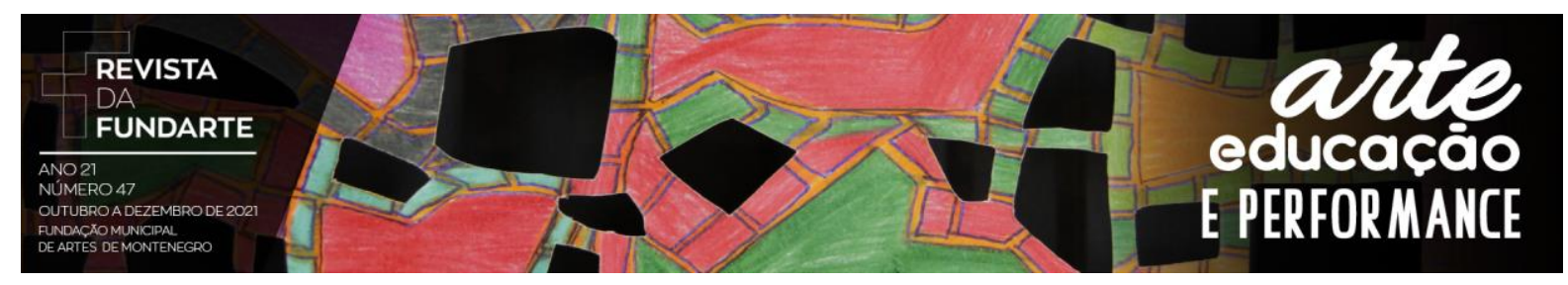

desenhos compõem um sistema econômico - mas que toda a significância disso deve ser entendida em termos de uma economia psíquica. (TRODD, 2008, p. 81).

A economia psíquica está atrelada à prática artística que não explora a criação nem a proliferação deliberada das imagens, mas utiliza seus referenciais e seu mundo imagético subjetivo de modo a permitir que cada imagem ganhe seu tempo. Seja reelaborada por outros meios, e permaneça sob o domínio do artista para ser livremente desdobrada a partir das demandas intrínsecas do processo criativo. O compromisso do artista não é com a multiplicação e propagação de imagens, e sim com o empenho em impulsioná-las a partir do ritmo de elaboração exclusivo do fazer. Pelo mesmo motivo Klee recortava e recombinava fragmentos da sua própria obra, que incluía o seu livre trânsito em reaver inclusive seus desenhos de infância armazenados no catálogo do artista. A economia psíquica trata de respeitar o tempo das imagens e antes disto, o tempo de elaboração delas no processo criativo.

O empenho de estender tanto quanto possível um pensamento em torno de um conceito expande a concepção já tão esmiuçada no campo da arte, ao pensar os "desdobramentos" poéticos e conceituais de um fazer. Retomando Paul Klee, a ideia de desdobrar me leva a considerar que, para o artista, o processo de transferência de imagem travava um paralelo com a repetição do gesto e para tanto, da doutrina da mão. A repetição que perseguia as linhas tracejadas de um desenho antigo, reproduzia um movimento contínuo que convoca através da prática, a memória.

As transferências de óleo são um sistema de reinscrição nas linhas dos desenhos existentes, uma forma de treinar a mão. O reconhecimento básico de que, ao aprender a desenhar, é a mão que deve ser treinada remonta, pelo menos, aos exercícios da Renascença no estúdio. Mas, como testemunham os relatos de seus alunos, foi algo que Klee também enfatizou, que é no treinamento das operações da mão em que reside a chave da realização gráfica: 'mantenha sua mão em prática', costumava dizer. (TRODD, 2008, p. 82-83).

A operação de retraçar as linhas de um desenho preexistente é uma forma de memorização. Ao refazer o gesto, seguindo o percurso das linhas originais, Klee ignora o resultado que sequer vê para concentrar-se no gesto que deve ser 


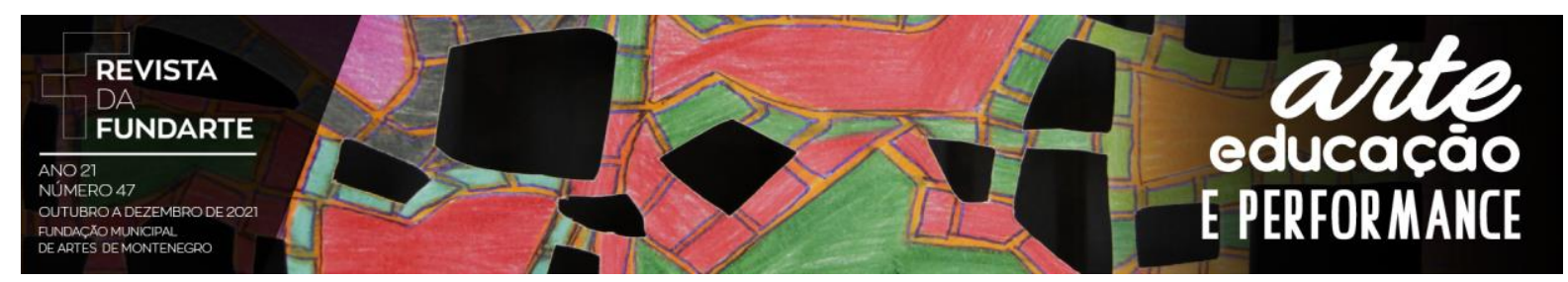

rememorado. Diante da hipótese levantada por Tamara Trodd, a repetição leva, conscientemente ou não, à memorização.

A transferência da imagem sistematizada por Paul Klee, remete à história do desenho no que tange a utilização de técnicas que visam treinar a mão e o corpo na prática de memorização. Como na operação de uma máquina em que certos movimentos são aprendidos através da repetição sincronizada dos gestos. Ao evocar a ideia da maquinaria, recordo de um brinquedo da infância que recorre também a repetição e registro dos gestos: a lousa mágica. Ela retém marcas que, tão logo são produzidas, desaparecem com o levantar do anteparo que recebeu as inscrições. Sabendo que todos os traços e gestos registrados pela lousa podem ser facilmente apagados, sem deixar rastros, há plena liberdade de criação, o que permite as experimentações mais diversas. Algo muito parecido com a lousa mágica é sugerido por Tamara Trodd sobre um instrumento capaz de reinscrever ao mesmo tempo que mantém um rastro permanente. Ela ressalta, associando à Freud, um aparato chamado Wunderblock.

Freud publicou, por volta de 1925, o texto "Uma nota sobre o bloco mágico" que compara a capacidade da memória com o Wunderblock, traduzido por "Bloco mágico" e algo similar ao brinquedo a que me referi por "lousa mágica"3. O princípio é basicamente o mesmo, inclusive, a estrutura física, ao passo que mudam-se apenas os materiais de que são feitos. A base consiste de uma prancha com um anteparo fixado em frente. A prancha do brinquedo era plástica, a mencionada por Freud era de resina ou cera castanha escurecida. $O$ anteparo - camada que fica acima da prancha - pode ser de plástico, celofane ou qualquer material transparente e móvel.

O bloco mágico referido por Freud possui uma camada dupla do anteparo. Ele mesmo explica que "A camada superior é um pedaço transparente de celuloide; a inferior é feita de papel encerado fino e transparente" (FREUD,1976, p. 287). Sobre estas superfícies não se usa nada que faça marcas permanentes sobre o

\footnotetext{
${ }^{3}$ Muito embora o brinquedo que hoje leva este nome não seja o mesmo ao qual me refiro pela simples diferença de que a lousa que conheci possuía um anteparo que recebia as marcas e as transportava para a camada de baixo, a prancha. A atual nominada "lousa mágica" não passa de um quadro branco escrito a caneta e apagado com apagador.
} 


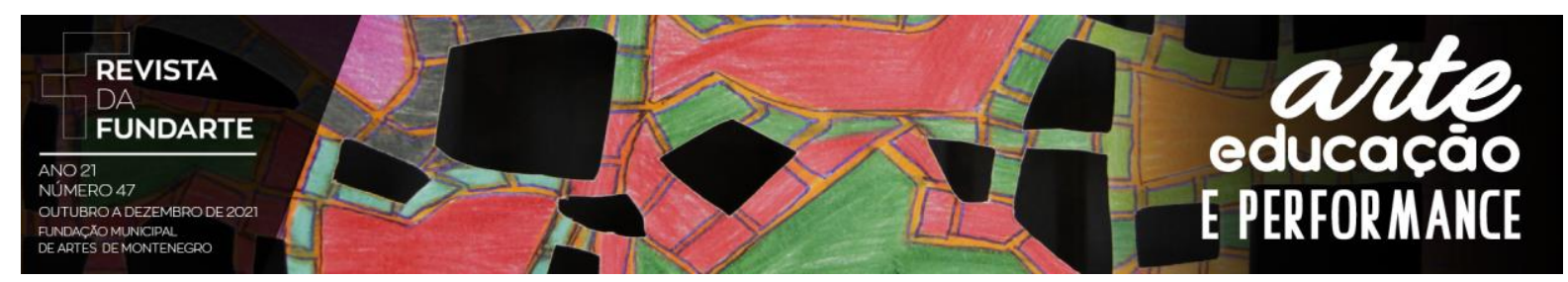

suporte. Um estilete ou ponta seca é o suficiente para realizar o registro apenas pela pressão exercida sobre a folha de celuloide - a primeira a receber o impacto da tensão. Finalizadas as inscrições, levanta-se o anteparo e tudo o que fora escrito desaparece e assim, continuamente.

O bloco mágico ou Wunderblock requer do usuário um conjunto de movimentos de mãos. A escrita na superfície, o levantamento do anteparo, uma atividade rítmica que Freud descreve assim

Se imaginarmos uma das mãos escrevendo sobre a superfície do bloco mágico, enquanto a outra eleva periodicamente sua folha de cobertura da prancha de cera, teremos uma representação concreta do modo pelo qual tentei representar o funcionamento do aparelho perceptual da mente. (FREUD, 1976, p. 289).

Neste trecho há dois aspectos relacionados, porém de origens distintas. O primeiro é mecânico e diz respeito ao movimento das mãos para a frente e para trás. O que pode ser compreendido como estrutura de realização das transferências de óleo. A mão inscreve a transferência no suporte ao mesmo tempo que transporta os seus dados para a memória, simultaneamente.

Vinculando mãos e memória, através do gesto, o funcionamento do bloco mágico de Freud é uma analogia ao desempenho da memória e do aparelho perceptual. O que faz com que a última superfície sobre a qual estão os sulcos inconscientes marcados pelo estilete "fosse uma parte materializada de meu aparelho mnêmico que, sob outros aspectos, levo invisível dentro de mim" (FREUD, 1976, p. 286). Ou seja, depois de repetir pelo gesto, os dados duplicados são armazenados na memória para que ela possa escolher reproduzir a qualquer momento a informação gravada. Informação ou imagem que, com sorte, escapará mais ou menos às eventuais deformações a que estaria sujeita na mente. Na esteira desta analogia, retomo as abarrotadas pastas de desenhos de Paul Klee que seriam tanto um reservatório físico de memória, quanto uma representação da própria memória do artista, treinada em repetir e reproduzir um desenho em várias cópias.

Segundo Freud, esses são os dois atributos essenciais da faculdade de memória que qualquer modelo externo proposto deve possuir: primeiro a eficácia de manter um traço permanente, uma estrutura fixa já processada. Em segundo lugar, 


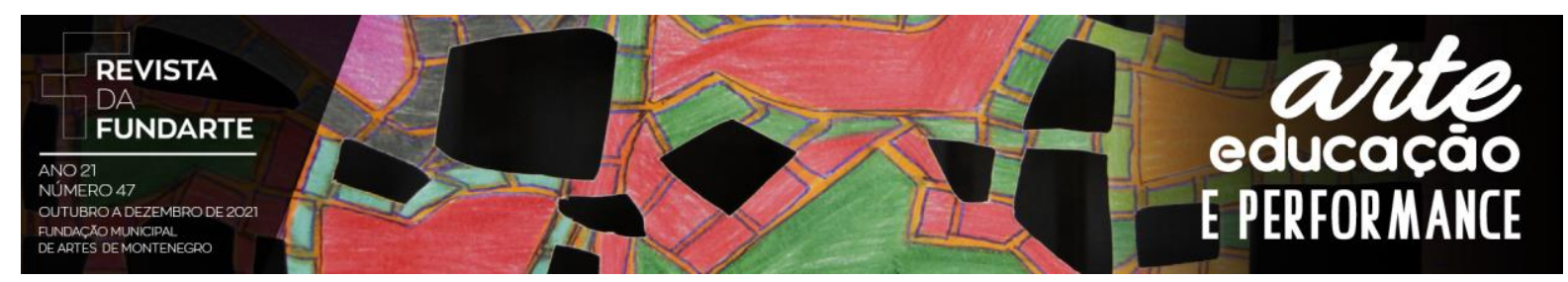

apresentar uma superfície limpa a novos estímulos que se manterão continuamente renovados. Há, portanto, a possibilidade de criar novos registros sem ter que eliminar os antigos, simultaneamente. Para Freud, o nosso aparelho psíquico possui "uma capacidade receptiva ilimitada para novas percepções e, não obstante, registra delas traços mnêmicos permanentes, embora não inalteráveis" (FREUD,1976, p. 286).

Durante a manipulação de qualquer um dos aparatos de transporte e criação de imagem, a inscrição que marca o suporte segue em direção à camada subjacente da prancha e é realizada em dois tempos. A inscrição acontece no presente e as marcas que são encontradas como forma de registro do ato estão no passado. $A$ linha tracejada pela transferência é invisível para o artista no momento em que acontece porque aparece visível somente embaixo da folha de papel sobre a qual a ponta é pressionada. O momento que sucede o levantar da primeira camada de papel é a revelação do registro das marcas realizadas no instante anterior que, apesar do frescor de que é embebido pelo envolvimento da experiência, faz parte do passado. "E é justamente por que as imagens não estão 'no presente' que são capazes de tornar visíveis as relações de tempo mais complexas que incumbem a memória na história (DIDI-HUBERMAN, 2012, p. 213).

Para Deleuze é evidente "que a imagem não está no presente. No presente está aquilo que a imagem 'representa', mas não a própria imagem. A imagem mesma é um conjunto de conexões de tempo cujo presente apenas decorre" (DELEUZE, 2003, p. 270). As junções temporais não são vistas na percepção comum, mas na imagem, desde que ela seja criadora. Segundo Deleuze, a imagem "torna sensíveis, visíveis, as conexões de tempo irredutíveis no presente". 4 Sua elaboração pressupõe várias camadas de tempo distintos, inclusive do passado, um tempo de retardo. A percepção deste atraso, compreendido como uma espécie de retardamento ou um delay, é inerente ao processo de realização da transferência. Essa temporária suspensão provoca a sensação de que os traços subjacentes não podem ser percebidas na íntegra, e de fato não o são.

\footnotetext{
${ }^{4}$ Deleuze aborda especificamente a imagem cinematográfica, em movimento, em entrevista de 1986, no texto Le cervau, c'est l'ecran, ou O cérebro e a tela.
} 


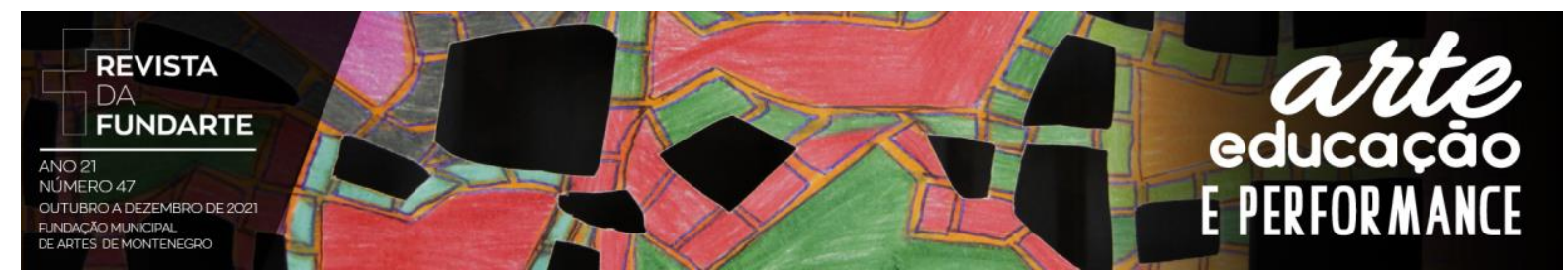

Como não recordar da experiência infantil de desenhar com o dedo na janela de vidro embaçado. As primeiras linhas desvanecem vagarosamente enquanto as sequentes bem definidas, avançam para logo dissipar. Em instantes o vidro está completamente fosco e renovado para ser marcado novamente, como "a memória, já que cada acontecimento é imediatamente substituído por outro que igualmente nos excita por um momento, mas sem deixar qualquer vestígio" (BONDíA, 2002, p. 23). A analogia do vidro embaçado e do processo de transferência metaforiza $o$ modelo de memória humana que trabalha no espaço e tempo de perdas, demonstrada pelo seu caráter instável, fragmentária, imprecisa.

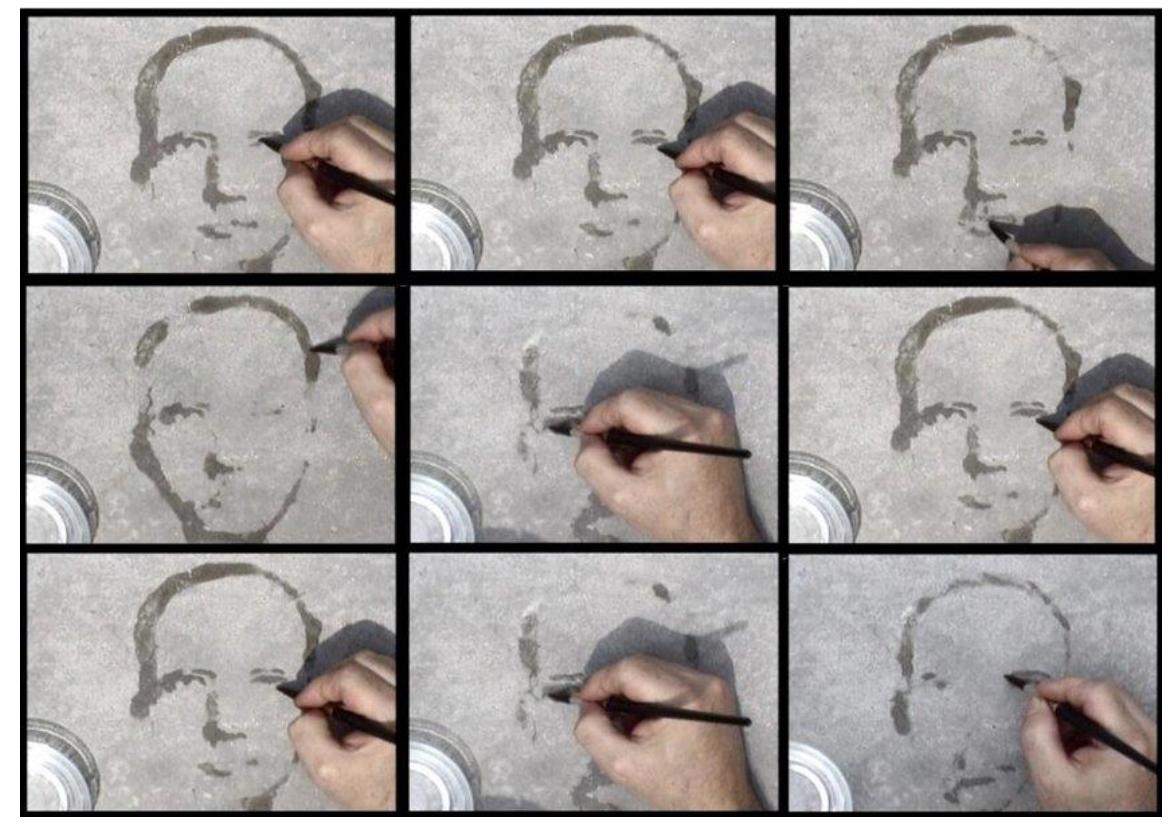

Figura 4: Óscar Muñoz. Re/trato, vídeo 28', 2004.

Os fragmentos das linhas que aparecem e desaparecem no anteparo rabiscado descrevem um processo de constante descoberta, algo exposto pela experiência que o efêmero registro em vídeo de Oscar Muñoz mostra. O artista colombiano trata da memória e sua potencial capacidade de desaparição na obra Re/trato (Figura 4) 5 . Pintando com um pincel embebido de água sobre uma superfície de cimento quente, ele traça linhas que ensaiam retratos parciais, e sempre parciais, porque a água logo evapora e os faz desaparecer, antes que o retrato possa ser concluído. Diz o artista sobre a prática de ateliê que no

\footnotetext{
${ }^{5}$ Vídeo disponível pelo link: $w w w . y o u t u b e . c o m / w a t c h ? v=y E u V v 0 K 10 \mathrm{kw}$
} 


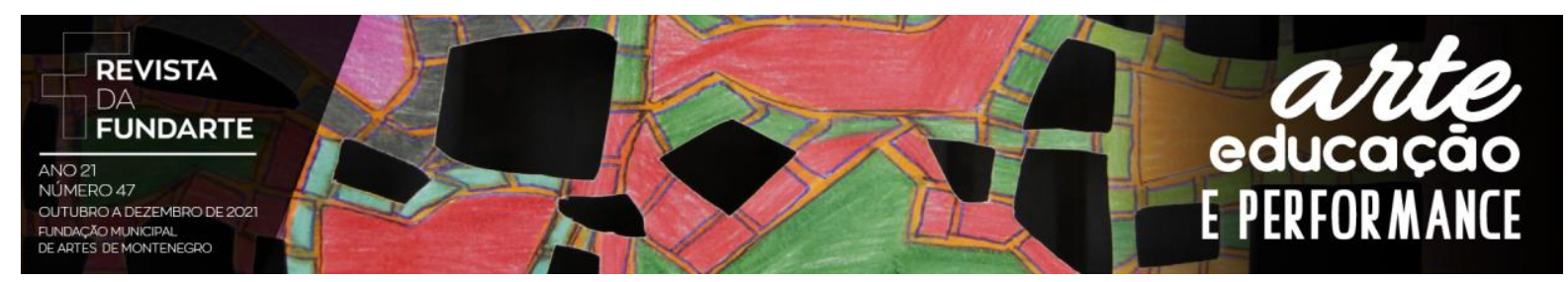

[...] momento em que a tinta entra em contato com o suporte ela pode ou não converter-se em um documento. É o que metaforicamente falando poderia ser o momento em que nós fixamos uma lembrança na memória ou não. Este lugar onde se constituem e consolidam as recordações. (MUÑOZ, 2012). ${ }^{6}$

No vídeo Re/trato, esse suporte, segundo o artista, é também uma metáfora do instante em que se consolida uma imagem que na fotografia poderia ser 0 momento em que ocorre a fixação da fotografia, e uma obra em papel, quando a tinta seca e imprime suas marcas. É o instante em que a obra acontece ou não, é o momento em que as coisas borram ou se fixam. Este trabalho joga com o desejo de Óscar Muñoz de manter acesa a memória e a frustração que pode vir da tentativa de fixá-la. Como o retrato nunca é terminado e o rosto não se completa, o espectador é compelido ao esforço de lembrar e reconstruir a imagem em sua mente. A busca pela imagem integral pode mudar para o espectador, visto que ele não possui uma estrutura permanente dela. $\mathrm{O}$ artista acredita que algo que geralmente funciona com o fugaz, com o instante, pode ter um efeito duradouro, da mesma forma que uma experiência emocional intensa ultrapassa a experiência real do trabalho (HERZOG, 2004).

Voltando a pensar na obra de Paul Klee, a relação da transferência com a memória tanto preserva o desenho e a memória, quanto os consome, por meio da transformação inerente ao processo. É um método de mecanização que reconfigura ambas as partes. Relacionada à memória está o processo de criação dos desenhos que requer um conjunto de procedimentos sob os quais um agrupamento de páginas são intercaladas, sobrepostas e posteriormente processadas. Exatamente os mesmos movimentos correlatos da própria memória e da sua operacionalidade. Isto é, momentos vividos no cotidiano são continuamente intercalados, sobrepostos e processados pela memória. Nesta compreensão, o sistema de transferência de imagem faz uma correlação metafórica da estrutura da memória.

\footnotetext{
6 Traduzido por mim da entrevista de Óscar Muñoz concedida ao Museu de Arte Moderna de São Francisco e disponível em: www.sfmoma.org/watch/oscar-munoz-explores-memory-throughephemeral-materials/
} 


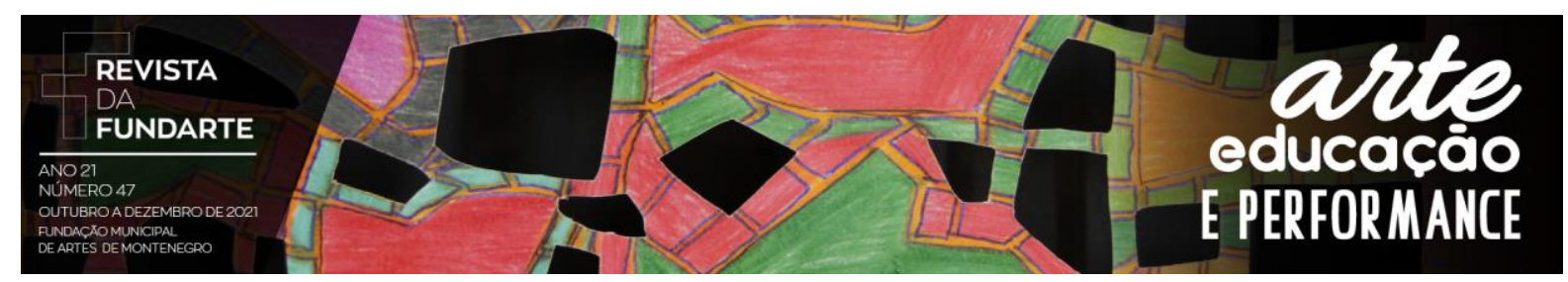

O desígnio das transferências é, sobretudo, a restauração e manutenção da imagem na memória. Contudo, o processo de transporte de imagem pressupõe uma ação predatória que consome e devora as imagens antes de fixá-las. O que é um dissenso frente as décadas de reflexão crítica acerca da fotografia enquanto repositório da memória. As técnicas mais antigas, como a pintura ou mesmo as transferências de óleo de Klee podem ser interpeladas como defesa contra essa ameaça. Aderindo aos meios poéticos do fazer manual envolvendo-se tanto com o valor substitutivo e transformador quanto com a duplicação e preservação das funções da memória.

A prática de transferência tem propósitos comuns à possibilidade de recordar, reelaborar e registrar a experiência de estar em contato com as memórias. De qualquer forma, o aparato de transferência de óleo desempenha a função de lembrar e de efetivar o lembrete através da materialização dos resíduos da imagembase. Lousa mágica e Wunderblock são sistemas de transferência que funcionam como instrumentos de modelagem para os processos de memória.

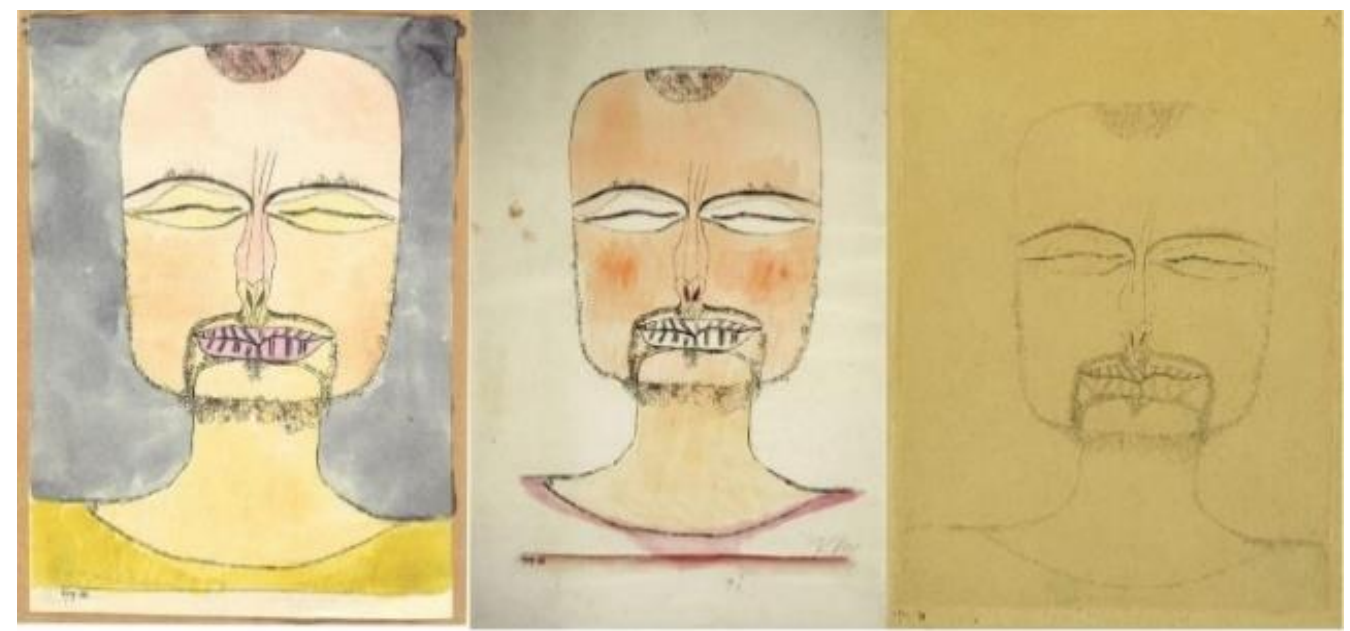

Figura 5: Paul Klee. Três versões reunidas do desenho Absortion reproduzido a partir da prática de transferência de óleo.

Para Klee, o transporte da linha de um desenho para outro suporte funcionava como uma das diversas funções de memória relacionadas à ideia de 


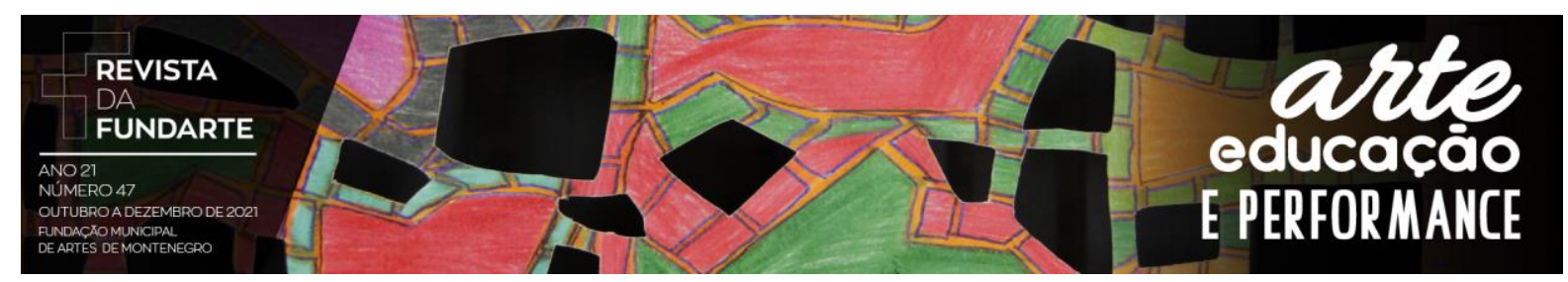

arquivo $^{7}$. Ambos os sistemas de transferência são ferramentas que assessoram a memória, a materializam e reelaboram.

A lousa mágica ou os processos de transferência descritos requerem uma manualidade repetitiva, relativamente simples de operar. Ela requer as duas mãos. Erguer e baixar as camadas de papel. Segurar a folha que recebe as marcas para impossibilitar qualquer alteração espacial a partir do mapeamento (que é mais mental do que físico) previamente estabelecido. Como uma máquina que opera para a frente e para trás, a sensação de construção se baseia na fisicalidade automatizada dos gestos orquestrados pelo corpo.

As manchas dispersas de tinta preta que maculam a superfície das obras de Paul Klee produzem uma forte sensação tátil. Apela-se à sensibilidade do espectador que pode ter a sensação do relevo ou textura do desenho ao imaginar passar a mão pela superfície do papel. O gesto do artista ao realizar as transferências de óleo e a sensação desejosa de provocar o espectador ao convite tátil conjuga a sua possível idealização de revelar pela cegueira, ou seja, despertar o desejo tátil. $O$ desenho intitulado Absorption (Figura 5) é um autorretrato em que o artista se representa desenhando com os olhos fechados. Também sem ver as linhas são decalcadas e reproduzidas sobre o suporte. Assim, o processo de transferência resguarda uma ideia de cegueira e a representação também, uma cegueira expressa como meio e como fim. Wassily Kandinsky, colega de docência na Bauhaus, afirma que o artista deveria cegar-se para o mundo externo, tese que permeia o livro "Do espiritual na arte". O processo de transferência de Klee evoca a ideia da cegueira atrelada ao começo do século XX e seu laço com a expressividade subjetiva que estimula o olhar do artista para o seu interior.

Em Absorption, as proporções dos três desenhos demonstram uma sequencialidade devido ao equilíbrio das formas que os faz reunidos, um conjunto harmônico, embora finalizados com tratamentos distintos. Através da extensa série de desenhos, Paul Klee exercitou a memória através da reprodução manual de

\footnotetext{
7 Derrida em "Mal de arquivo", cita o texto "Uma nota sobre o Bloco Mágico" de Freud como referência a sua teoria. $\mathrm{O}$ autor faz do aparelho psíquico uma metáfora do bloco mágico para pensar na memória arquivada ao afirmar que não há memória sem arquivo.
} 


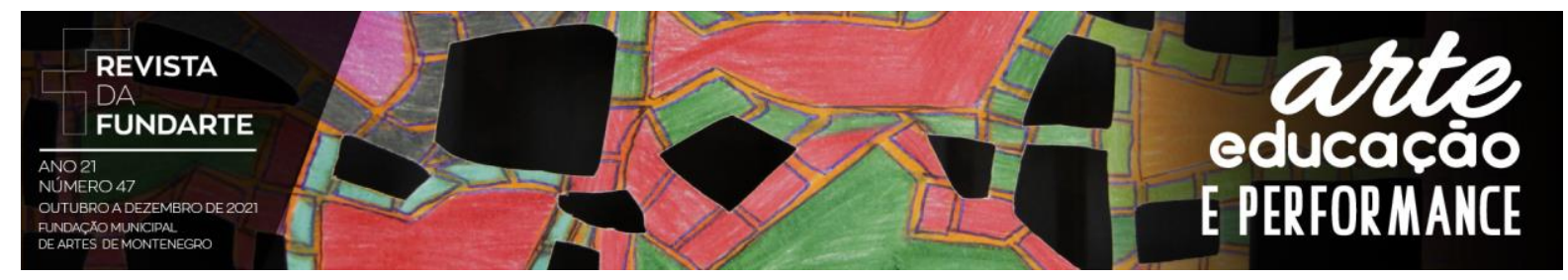

desenhos, fixou imagens e reproduziu ideias no que parece ser uma coerência poética dentro das estruturas criativas desenvolvidas pelo artista.

\section{Referências:}

BONDÍA, Jorge Larrosa. Notas sobre a experiência e o saber de experiência. Revista brasileira de educação, 19: 20-28. 2002.

DELEUZE, Gilles. Le cervau, c'est l'ecran. (1986), Deux Régimes de Fous. Textes et entretiens, 1975-1995, ed. D. Lapoujade, Paris: Minuit, 2003.

DERRIDA, Jacques. Mal de arquivo: uma impressão freudiana. Rio de Janeiro, RJ: Relume-Dumará, 2001.

DIDI-HUBERMAN, Georges. Quando as imagens tocam o real. PÓS: Revista do Programa de Pós-graduação em Artes da EBA/UFMG, v.2, n.4, p. 204-219, nov. 2012.

FREUD, Sigmund. Uma nota sobre o bloco mágico, O mecanismo psíquico do esquecimento, Lembranças encobridoras. FREUD, Sigmund. Obras psicológicas completas. Rio de Janeiro: Imago, 1976.

HERZOG, Hans-Michael (ed.). Cantos cuentos colombianos: arte colombiano contemporáneo. Hatje Cantz Pub, 2004.

MUÑOZ, Óscar. Entrevista concedida ao Museu de Arte Moderna de São Francisco e disponível em: http://sfmoma.org/watch/oscar-munoz-explores-memory-throughephemeral-materials/>. Acesso em: 22 Mar. 2021.

TRODD, Tamara. Drawing in the Archive: Paul Klee's Oil-Transfers. Oxford Art Journal 31.1. p. 75-95. 2008. 